\title{
Thief zone identification and classification in unconsolidated sandstone reservoirs: A field case study
}

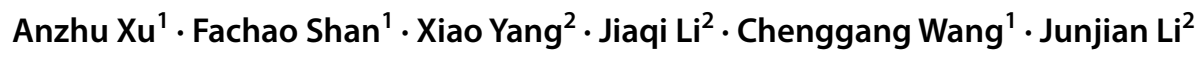

Received: 6 July 2021 / Accepted: 15 July 2021 / Published online: 28 July 2021

(c) The Author(s) 2021

\begin{abstract}
Channeling between injectors and producers leads to bypassed oil left in the reservoir, which is one of most common reasons that wells in mature oil fields experience high water cut after long-term waterflooding. Identification and evaluation of the higher permeable channels (thief zones) are the key to effectively plug these thief zones and improve the conformance of water flood. This study applies three different methods to identify and evaluate the thief zones of a water injection project in North Buzazi Oilfield, a thick-bedded unconsolidated sandstone heavy oil reservoir in Manghestau, Kazakhstan. The thief zones, which evolve as a result of formation erosion and sand production, are identified and classified with respect to four different levels of significance using fuzzy comprehensive evaluation, production/injection profile method and pressure index (PI) methods. Good consistency is observed among the identification results using these methods. Finally, we present two ways to quantitatively evaluate the characteristics of the thief zones using water-oil-ratio as the input, which can be readily applied for future field development design.
\end{abstract}

Keywords Water flooding $\cdot$ Thief zone $\cdot$ sandstone

\section{Introduction}

After long-term water flooding, dissolution and erosion of the formation lead to an increase in pore size and permeability. Under the combined effects of formation heterogeneity and gravity differentiation, some zones with large porosity and high permeability will evolve into thief zones that cause channeling between injectors and producers, resulting in ineffective circulation of injected water.

There have been different methods proposed for the identification and evaluation of the thief zones. Well logs, such as injection and fluid production profile logging (Xiang et al. 2002), is one of the most common ones. Sometimes the formation of thief zones could be recognized from coring and observing the core's lithology, color (i.e., the thief zones are often white and washed cleanly) and oil content. To obtain the quantitative evaluation of thief zones, the mathematical

Junjian Li

junjian@126.com

1 PetroChina Research Institute of Petrol Exploration and Production: Research Institute of Petroleum Exploration and Development, Beijing, China

2 China University of Petroleum, Beijing, China model applicable to fluid flow under the influence of thief zones is established and solved, from which several methods are proposed. For example, the well-known modifiedHall analysis (Kabir and Izgec 2009) is developed based on single-phase, steady state, radial flow of liquids. Some studies proposed straightforward calculation for thief zone parameters using injection/production data-based simplified one-dimensional flow models (Zhilin et al. 2001; Yuetian et al. 2003). Pressure responses of the production and injection wells have also been used to identify and evaluate the thief zones quantitatively via well test (pressure transient) analysis based on solving the transient liquid flow problem analytically (Zhao et al. 1994; Feng et al. 2013) or numerically (Li et al. 2016).

In recent decades, many studies have used tracers (interwell tracer testing) to identify the direction and velocity of the fluid flow in the porous medium(Yueming et al. 1994; Shuxia and Yueming 2002; Limei et al. 2003), from which the thief zones can be evaluated from the transport of the tracer (Calhoun 1953; Lu et al. 2021a, b). This is currently the most effective and reliable method but presents the limitation of high cost and heavy workload. Moreover, recent developments also show that streamline simulation is an advantageous tool to identify the spatial distribution of thief 
zones via history matching against production data (Vargas-Guzmán et al. 2009). In practice, two or more of these methods are usually implemented together to improve the efficiency and reliability of the identification and evaluation of the thief zones (Felsenthal and Gangle 1975; AbbaszadehDehghani 1982; Asadi et al. 2005; Al-Dhamen et al. 1998).

In this paper, we present the study of identifying and classifying the thief zones in North Buzazi Oilfield with respect to different significance levels using three different methods: a fuzzy comprehensive evaluation method using reservoir properties obtained from well logs, a vertical heterogeneity chart under production/injection profile concept and a pressure index (PI) chart based on a newly proposed dimensionless PI value calculated from well pressure response.

\section{Thief zones identification in North Buzazi Oilfield}

The North Buzazi Oilfield is a heavy oil reservoir with edge/ bottom water and gas cap. The formation is Cretaceous and Jurassic unconsolidated sandstone. The average reservoir permeability is $200-3000 \mathrm{md}$, and the crude oil viscosity is $356-527 \mathrm{mPa}$ s, the reservoir temperature is $22-31{ }^{\circ} \mathrm{C}$, and the salinity of formation water is above 60,000PPM. As shown in Fig. 1, significant sand production is observed in some oil production wells, and the injection pressure of the water injection wells is greatly reduced, indicating that the channeling is due to the water injection and evolution of thief zones. Based on well log data, the interpolated distributions of the porosity and permeability are shown as in Fig. 2. In this study, we apply fuzzy evolution method to identify and classify the thief zones.
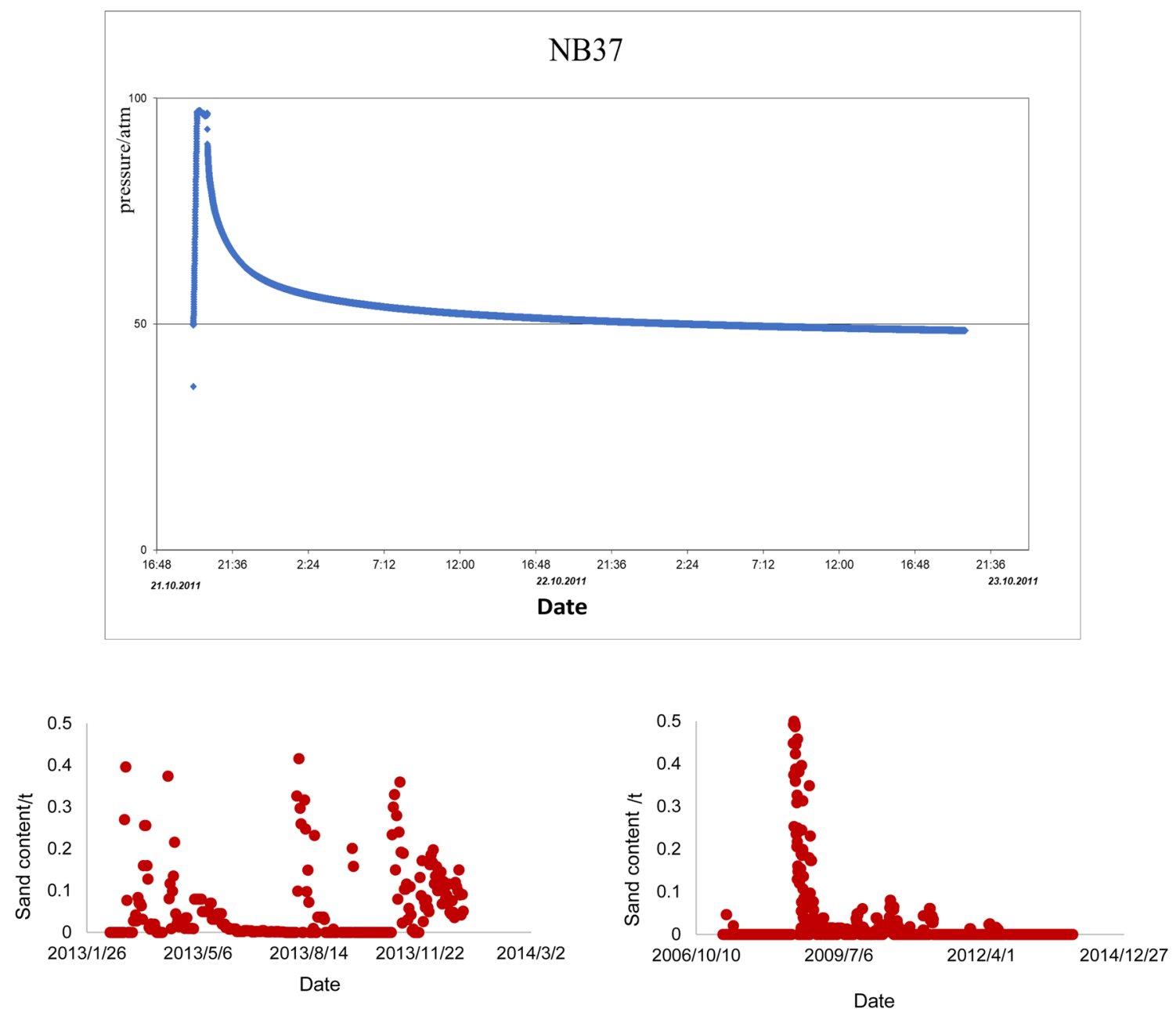

Fig. 1 (Top) Pressure drop data of Well NB 37; (Bottom left) Sand production of Well NB6695;(Bottom right) Sand production of Well NB6182 
Fig. 2 (Top) Porosity and (bottom) permeability distributions of North Buzazi Oilfield

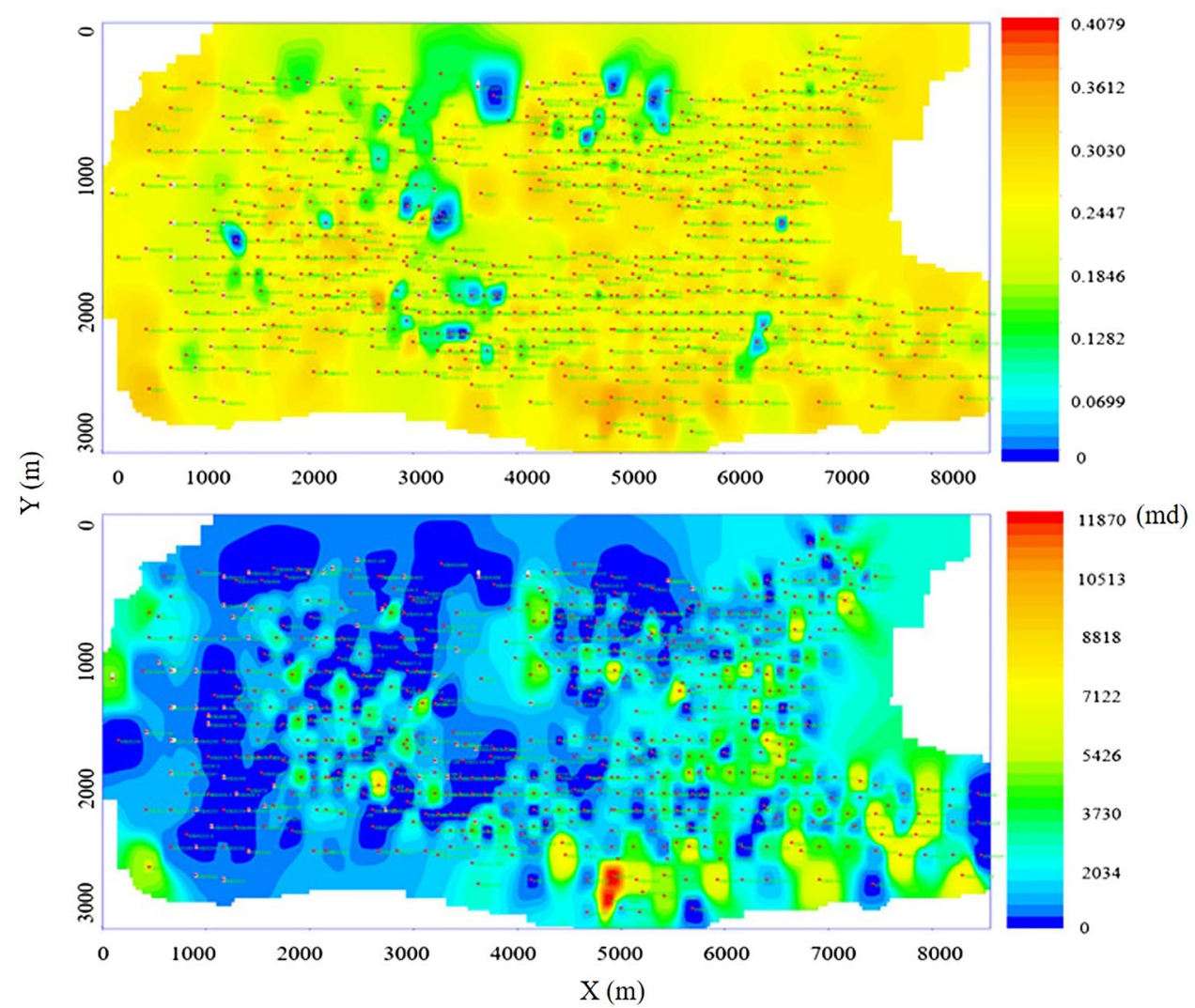

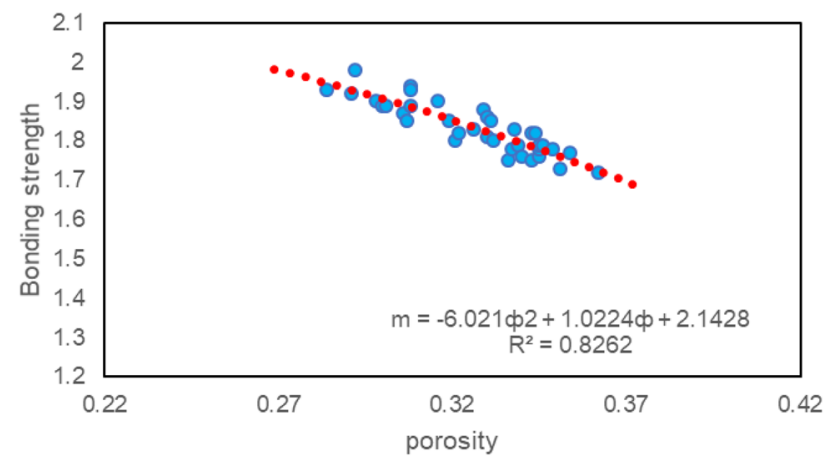

Fig. 3 The relationship between the cementation index $(m)$ and porosity $(\phi)$ of the North Buzazi oilfield

\section{Fuzzy comprehensive evaluation for the identification of thief zones}

Fuzzy comprehensive evaluation method is an evaluation method based on fuzzy mathematics. Qualitative evaluations are converted to quantitative evaluations based on the membership degree theory of fuzzy mathematics, that is, using fuzzy mathematics to make an overall evaluation of things or objects restricted by multiple factors. It can better solve problems which are vague and difficult to quantify and is thus suitable for solving various non-deterministic problems.
The formation and evolution of the thief zones are affected by both static factors (geological conditions) and dynamic factors (injection and production conditions). In this paper, eight factors are selected, including three static factors and five dynamic factors, to characterize the cause of formation and evolution of the thief zones. They are detailed as follows:

Static factors:

(1) Permeability ratio: permeability ratio is the ratio of maximum permeability $\left(K_{\max }\right)$ to minimum permeability $\left(K_{\mathrm{min}}\right)$.

(2) Degree of cementation: an empirical relationship is established between the cementation index and porosity of the unconsolidated sandstone reservoirs in North Buzazi (Fig. 3). The lower the cementation strength, the greater the possibility of developing a thief zone.

(3) Clay content: Clay refers to the detrital material with a particle diameter of less than $0.01 \mathrm{~mm}$. Clay content is also called shale volume, which refers to the ratio of the volume of shale to the total volume of the rock. If the formation presents low clay content, after long-term water injection development, the shale cementation on the rock pore surface is weakened, and sands migrates with the injected water, resulting in sand production, which leads to the increase in the permeability and per-

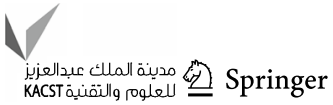


meability of the formation. The clay content is determined by well log data.

Dynamic factors:

(1) Dimensionless cumulative water injection: the ratio between the water injection of a well group and the average water injection of the whole area. The larger the value is, the greater the possibility of forming a thief zone;

(2) The water-oil-ratio of the well group: the ratio between the water-oil-ratio of a well and the average wateroil-ratio of the well group. The larger the value is, the greater the possibility of forming a thief zone;

(3) Sand production: the larger the sand production, the easier it is to develop the thief zone;

(4) Increasing rate of water cut: the rising rate of water cut refers to the percentage of water rising for every $1 \%$ of geological reserves extracted;

(5) Dimensionless cumulative fluid production: the ratio between the fluid production of a well group and the average fluid production of the whole area. The larger the value is, the greater the possibility of forming thief zones.

The fuzzy comprehensive evaluation method consists of the following steps:

(1) The evaluation factor set The factor set is the construction of the fuzzy comprehensive evaluation index, including the influencing factors of the formation of the thief zone.

$$
U=\left\{\mu_{1}, \mu_{2}, \ldots, \mu_{m}\right\}
$$

(2) The fuzzy comment set The comment set is determined by the front plane and longitudinal heterogeneous classification.

$V=\left\{v_{1}, v_{2}, \ldots, v_{n}\right\}$

(3) The weight of each factorThe weight distribution of the evaluation factors used in this study is adjusted and determined combining the gray relational analysis method based on the results of dynamic and static analysis, and results are shown in Table 1:

Table 1 Weights distribution of the factors, and the upper and lower bounds of the factors of each inhomogeneity level

\begin{tabular}{|c|c|c|c|c|c|c|c|c|}
\hline & \multicolumn{3}{|l|}{ Static factor } & \multicolumn{5}{|l|}{ Dynamic factors } \\
\hline & $\begin{array}{l}\text { Permeability } \\
\text { ratio }\end{array}$ & $\begin{array}{l}\text { Degree of } \\
\text { cementation }\end{array}$ & Clay content & $\begin{array}{l}\text { Increasing rate } \\
\text { of water cut }\end{array}$ & $\begin{array}{l}\text { Sand produc- } \\
\text { tion }\end{array}$ & $\begin{array}{l}\text { Cumulative } \\
\text { water-oil-ratio }\end{array}$ & $\begin{array}{l}\text { Dimensional } \\
\text { cumulative } \\
\text { water injec- } \\
\text { tion }\end{array}$ & $\begin{array}{l}\text { Dimensional } \\
\text { cumulative } \\
\text { liquid injec- } \\
\text { tion }\end{array}$ \\
\hline Weights & 0.2857 & 0.5714 & 0.1429 & 0.088 & 0.158 & 0.158 & 0.298 & 0.298 \\
\hline \multicolumn{9}{|c|}{ Upper and lowe bounds of the factors used for each significance level of theif zones } \\
\hline Normal & $<2.21$ & $>1.85$ & $>35$ & $<0.0019$ & $<6.32$ & $<65.88$ & $<0.82$ & $<0.66$ \\
\hline Natural & $2.21 \sim 9.29$ & $1.80 \sim 1.85$ & $25 \sim 35$ & $0.0019 \sim 0.0045$ & $6.32 \sim 30.48$ & $65.88 \sim 293.94$ & $0.82 \sim 1.29$ & $0.66 \sim 1.54$ \\
\hline Developing & $9.29 \sim 22.40$ & $1.75 \sim 1.80$ & $15 \sim 25$ & $0.0045 \sim 0.0153$ & $30.48 \sim 64.97$ & $293.94 \sim 737.63$ & $1.29 \sim 3.39$ & $1.54 \sim 4.95$ \\
\hline Developed & $>22.40$ & $<1.75$ & $<15$ & $>0.0153$ & $>64.97$ & $>737.63$ & $>3.39$ & $>4.95$ \\
\hline
\end{tabular}

Fig. 4 Thief zone distribution obtained from fuzzy evaluation method

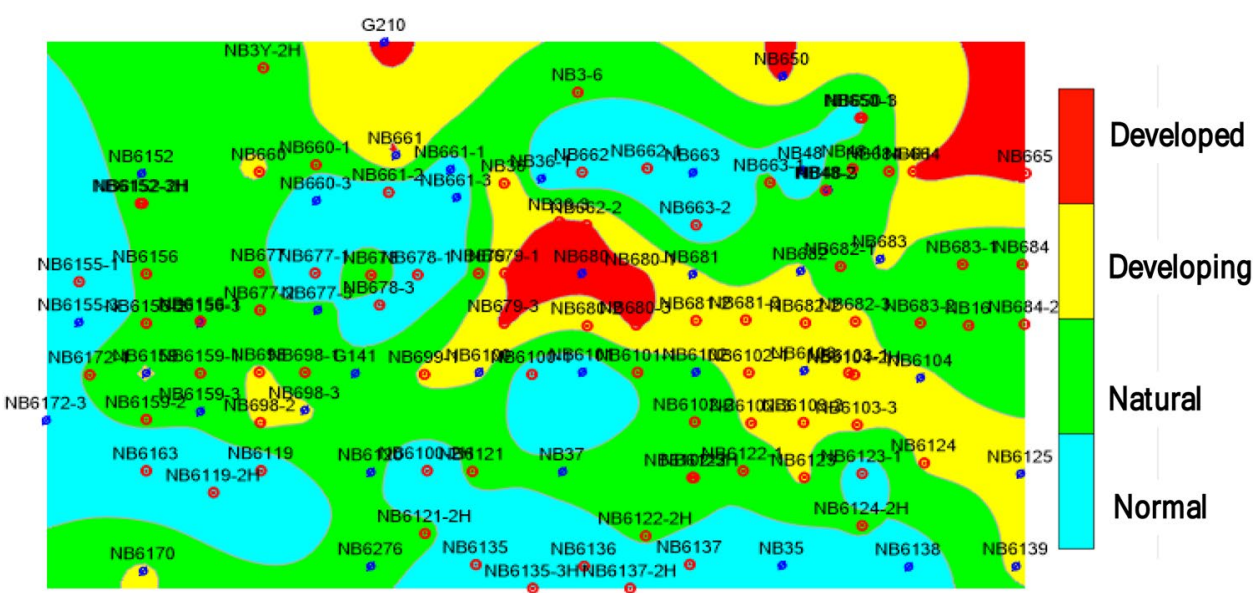




$$
A=\left[a_{1}, a_{2}, \ldots, a_{m}\right]
$$

(4) The membership functions

This work chooses to determine the membership function using the assignment method and the trapezoidal function.

(5) The fuzzy evaluation matrixFor a certain data point, the inhomogeneity level (thief zone significance level) and intercept in the two plates can be determined, and the value corresponding to the intercept can be substituted into the membership function of the corresponding inhomogeneity level to obtain the degree of membership, from which the planar and longitudinal heterogeneity qualitative fuzzy evaluation matrix $R$.

$$
R=\left[\begin{array}{cccc}
r_{11} & r_{12} & \ldots & r_{1 n} \\
r_{21} & r_{22} & & r_{2 n} \\
\vdots & \ddots & \vdots \\
r_{m 1} & r_{m 2} & \cdots & r_{m n}
\end{array}\right]
$$

(6) Fuzzy comprehensive evaluation The weight and the evaluation matrix are multiplied to obtain the final evaluation matrix.

$B=A \times R=\left[b_{1}, b_{2}, \cdots, b_{n}\right]$

Given the input reservoir properties (static factors) and well production/injection data (dynamic factors), we apply the fuzzy evaluation following the steps above, and results are given in Fig. 4. For this study, we defined four different levels of significance (normal, natural, developing and developed) for thief zone evolution as a result of erosion and sand production. Therefore, the subscript ' $n$ ' in Eqs. 2,
4 and 5, which denotes the level of classification, is equal to four. For each thief zone significance level (inhomogeneity level), the upper and lower bounds of the static and dynamic factors are determined following normal distribution, and values are given in Table 1.

\section{Production/Injection profile method}

The production/injection profile of oil and water wells characterize the thief zones along the vertical direction. In the vertical direction, layers of thief zones exhibit higher water and liquid flow. Two parameters, $H_{\text {as }}$ (strength of heterogeneity index of water injection) and $H_{a}$ (heterogeneity index of water injection), are defined and used as the horizontal and vertical coordinates of the evaluation chart discussed below. They are defined as:

$H_{\mathrm{as}}=\frac{\bar{A}_{s}}{A_{s, \max }}$

where $\bar{A}_{s}$ is the total water injection strength and equals to the ratio of total water injection volume and total thickness of the reservoir; $A_{s}$ is water injection strength of the thief zone layer, and $A_{s, \max }$ represents the highest water injection strength of all thief zone layers.

Table 2 The difference in permeability characterizes the development strength of the thief zone

\begin{tabular}{ll}
\hline $\begin{array}{l}\text { Permeability } \\
\text { contrast }\end{array}$ & Thickness ratio \\
\hline 1 & 0.2 \\
3 & 0.4 \\
5 & 0.6 \\
10 & 0.8 \\
20 & 1 \\
\hline
\end{tabular}
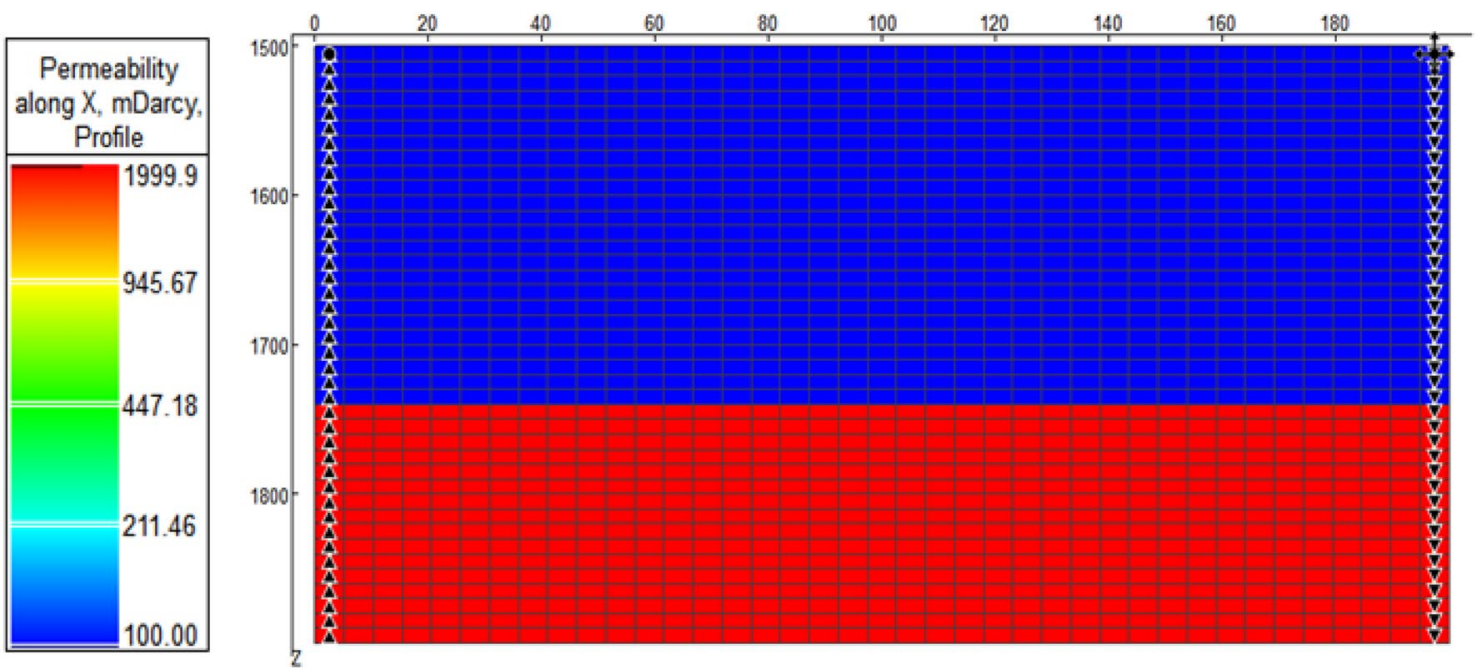

Fig. 5 Numerical simulation conceptual model of one injector and one producer 
Fig. 6 Standard chart of vertical heterogeneity evaluation of thief zones
Fig. 7 Evaluation chart of vertical heterogeneity of thief zones in North Buzazi Oilfield
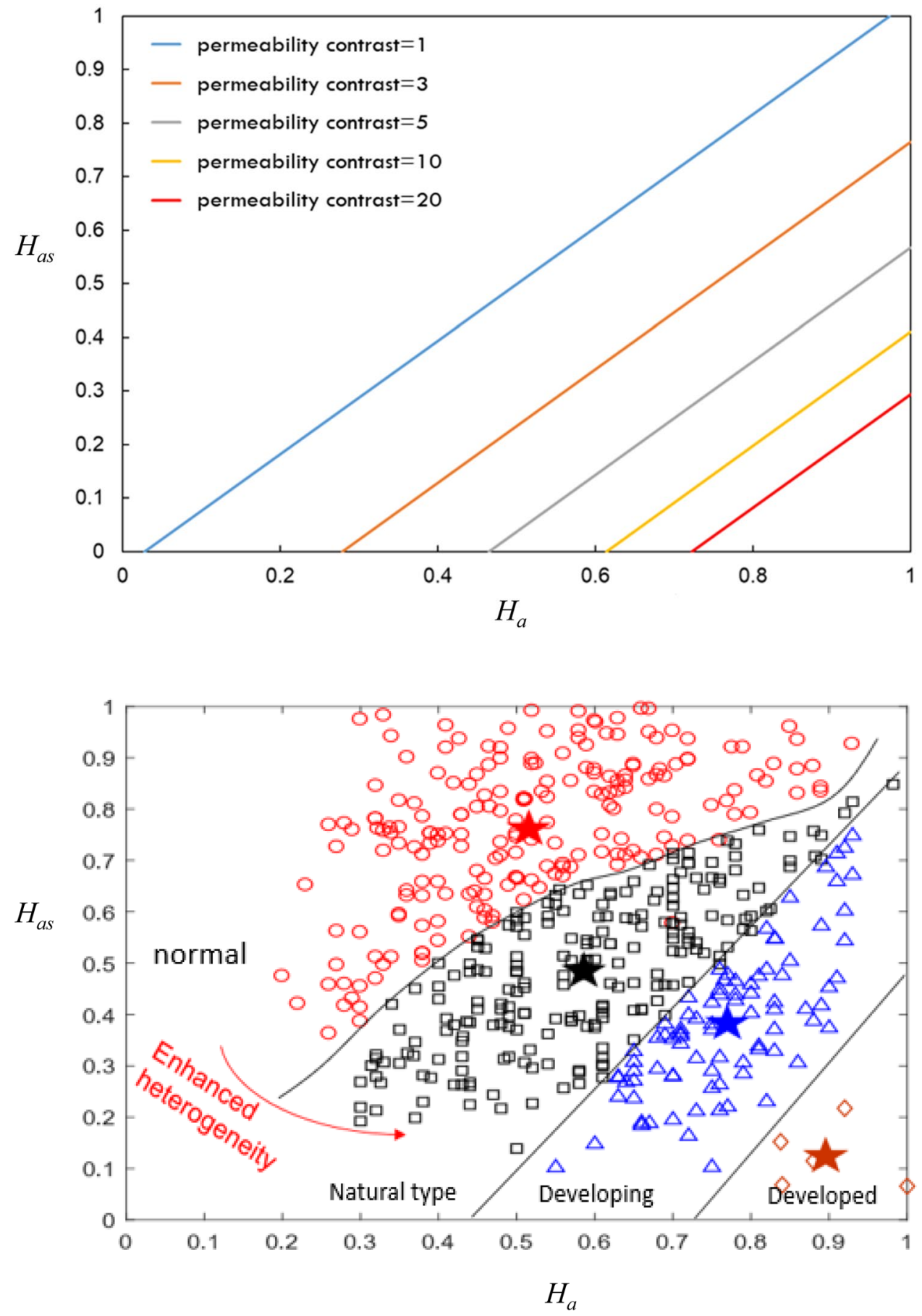

$H_{a}=\frac{A_{\max }}{A_{T}}$

where $A_{\max }$ is the maximum layer water injection volume among all layers; $A_{T}$ is the total water injection volume. It should be noted that both $H_{\text {as }}$ and $H_{a}$ are between zero and unity. The higher the $H_{\text {as }}$ is (the lower the $H_{a}$ is), the higher the heterogeneity.
A synthetic and conceptual model is structured with one injection and one production well using numerical simulation (Fig. 5). The permeability contrast and thickness ratio between the upper and lower layers of the model are used to characterize the thief zones depicted in Table 2 . Simulation data are used to calculate the $\mathrm{H}_{\mathrm{as}}$ and $\mathrm{H}_{\mathrm{a}}$ indices. The resulting straight lines, which are parallel to each other, are shown in Fig. 5. The straight line with permeability contrast of unity is the boundary of the vertical 
heterogeneity. When the data fall into the upper-left side of the straight line, it is considered that the formation is homogenous along vertical direction. When the value falls into the lower-right-side of the straight line, it is considered that there is a vertical heterogeneity between the injection well and the production well, and the heterogeneity of the data gradually increases from the upper-left to the lower-right-side.

Based on the standard chart shown in Fig. 6, the production/injection profile data collected from a total of 512 wells in North Buzazi is analyzed using Eqs.6 and 7 and plotted in Fig. 7. We further classify the thief zones with respect to the significance of the vertical heterogeneity using the $K$-means clustering algorithm detailed in Appen$\operatorname{dix} \mathrm{A}$.

\section{Pressure index method}

The pressure index (Pressure Index, PI) method is often used in conformance control and injection shutoff decision-making in waterflood projects. In the previous studies of PI method for the identification of thief zones, the temporal evolution of reservoir properties under water injection has always been conveniently neglected. We proposed a dimensionless PI value that considers the temporal variation of reservoir permeability before and after the formation of the thief zone, and thus eliminates the influence of the flow capacity of the formation on the pressure falloff data, leading to an accurate and effective identification of the thief zone.

The wellhead pressure $\left(p_{\mathrm{ws}}\right)$ of the water injection well after shut-in is the pressure falloff curve of the injection well. The pressure index (PI) value of the water well can be calculated as following:

$\mathrm{PI}=\frac{1}{t} \times \int_{0}^{t} p_{w s}(\Delta t) d t$

where PI is the pressure index value of the water injection well, $p_{\mathrm{ws}}(\Delta t)$ is the wellhead pressure as a function of shut-in time $\Delta t$.The PI value is inversely proportional to the formation flow coefficient $\mathrm{kh} / \mu$. Therefore, if the reservoir permeability is higher, the thickness is greater, and the fluid viscosity is smaller, the reservoir fluid in presents higher mobility and injectivity, and the PI value will be thus lower. On the other hand, the lower the water injectivity, the greater the PI value.

Though the evolution of the thief zone would affect the PI value, the PI value is a parameter that quantifies the overall flow capacity of the formation, rather than the characteristics of the thief zone. Without normalization with respect to the effect of reservoir initial flow capacity on the pressure falloff data, the PI value presented in Eq. 8 is unable to characterize the temporal variation of reservoir permeability before and after the development of the thief zone. Considering above, this paper uses the following dimensionless PI values (Sen 2012):

$\mathrm{DPI}=\frac{k_{i} h}{1.842 \times 10^{-3} q \mu} \cdot \mathrm{PI}$

where DPI is the dimensionless PI value;

$k_{i}$ is the original permeability of the reservoir, $\mu \mathrm{m}^{2}$;

$h$ is the effective thickness of the reservoir, m;

$q$ is the injection volume of the water injection well, $\mathrm{m}^{3} / \mathrm{d}$; $\mu$ is the fluid viscosity in the reservoir, $\mathrm{mPa} \cdot \mathrm{s}$;

Fig. 8 PI chart

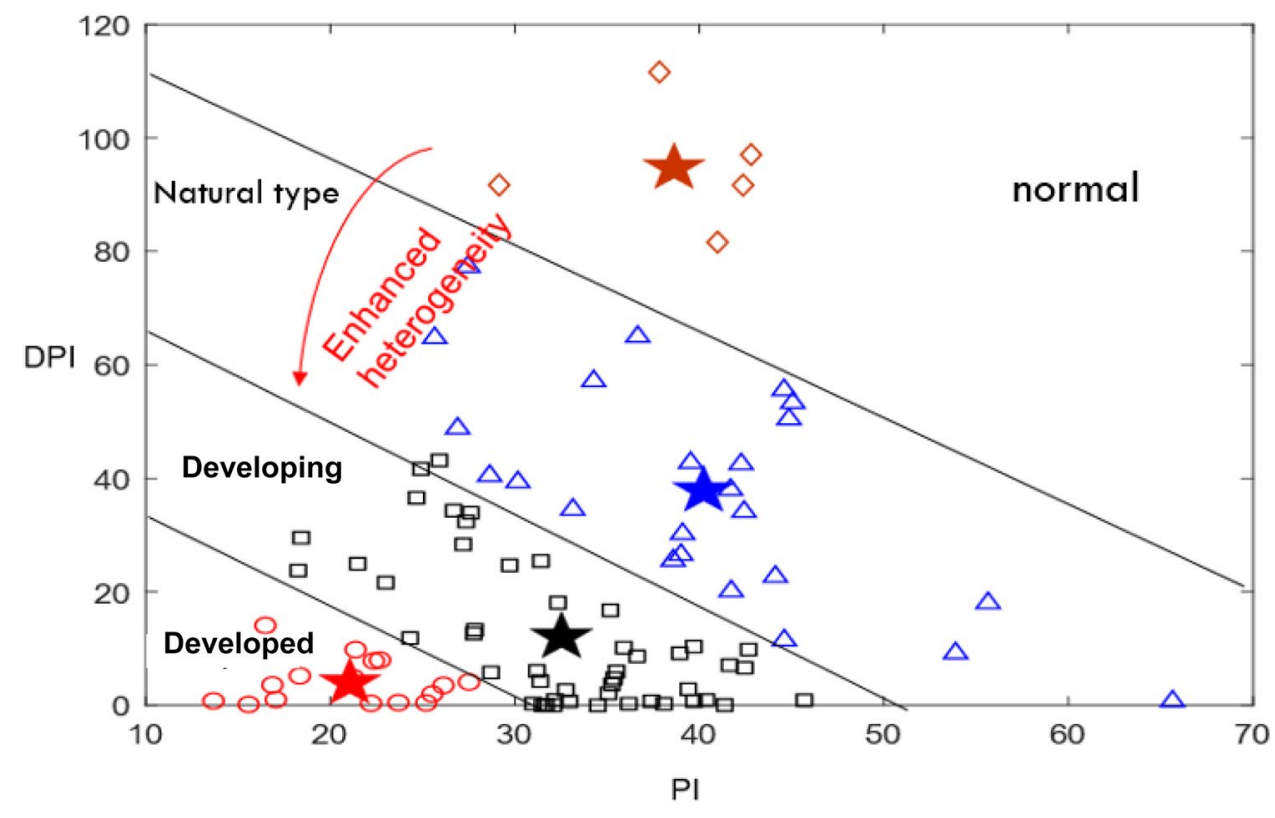



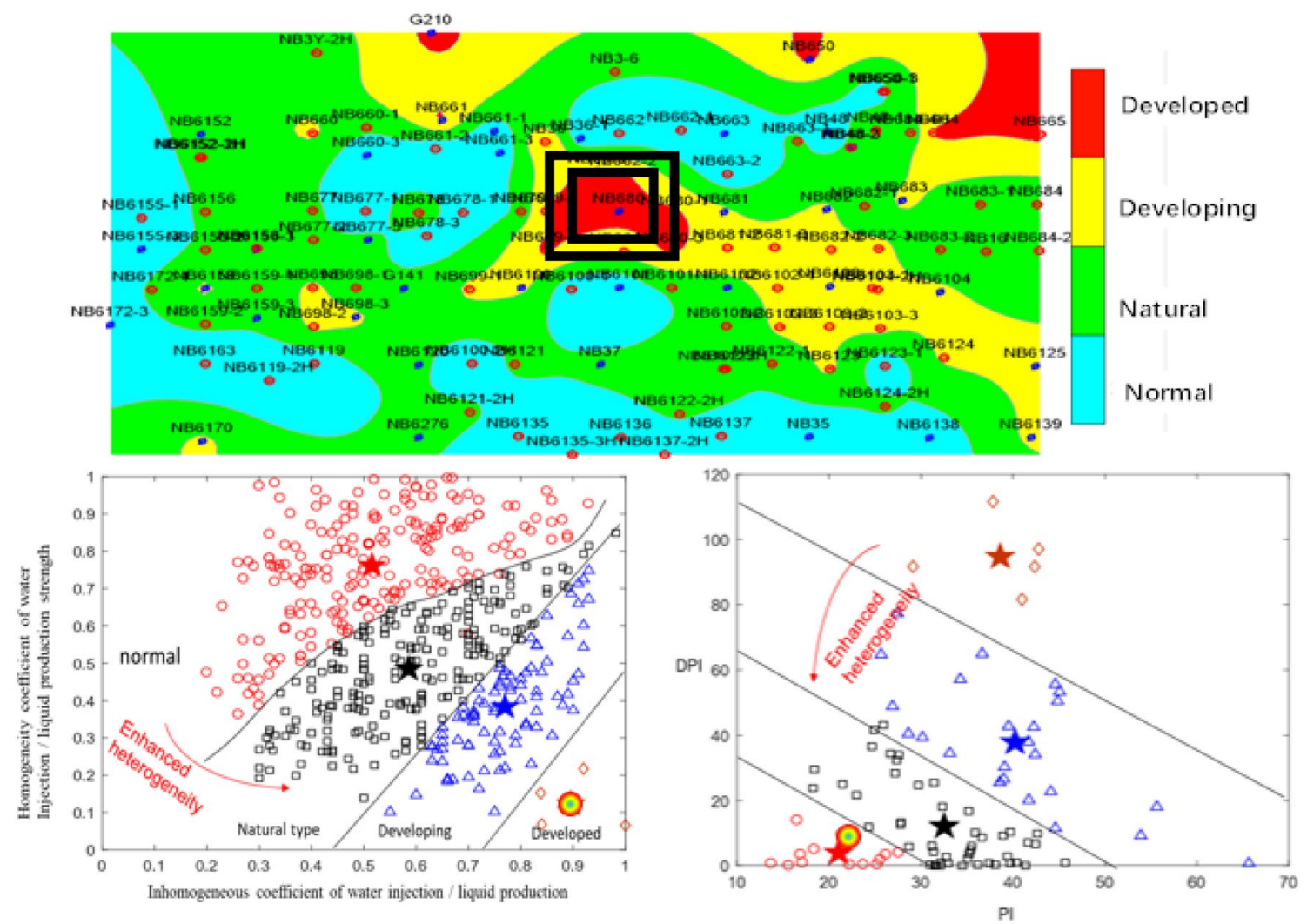

Fig. 9 Comparisons of the identification results of well group 680

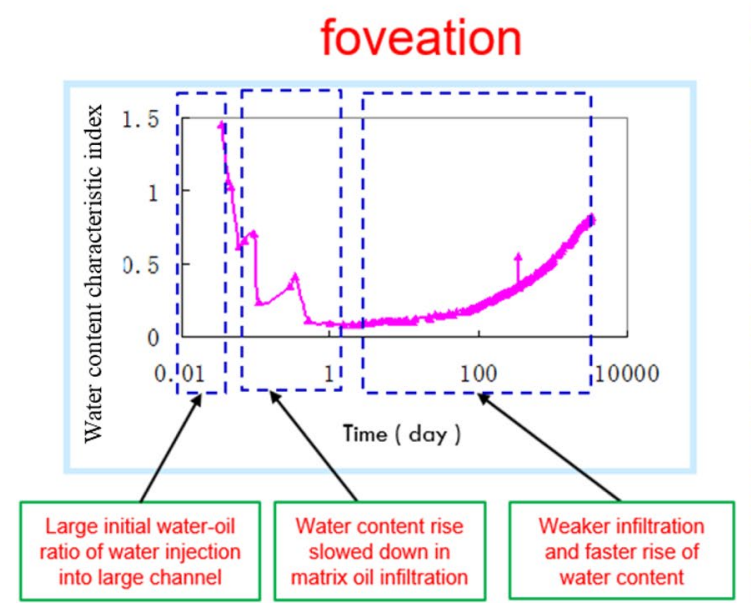

Typical thief zones of pipe flow pattern

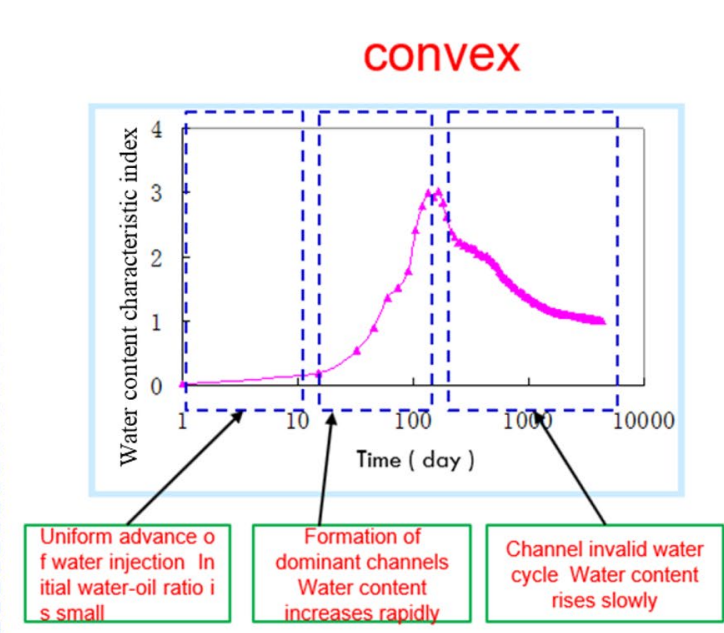

Typical seepage of zones

Fig. 10 Typical water cut index curves of different levels thief zones

PI is the PI value, MPa.

The PI and DPI characterize the flow capacity of the reservoir from two different perspectives. The PI value quantifies the overall fluid conductivity of the reservoir, while the dimensionless PI value quantifies the degree of enhancement of the fluid conductivity during the entire injection process. We found in practice that it be better to combine the two methods for the well selection step in conformance control and water shutoff process. Using Eqs. 8 and 9, we analyzed the pressure data collected from a total of 98 wells in North 
Buzazi field. Similarly, $K$-means clustering algorithm is implemented to classify the wells with respect to different significance levels of thief zones as shown in Fig. 8.

To showcase the applicability and reliability of the three methods (fuzzy evaluation, production/injection profile and PI chart) presented above, well group 680 is taken as a example, and the identification results are highlighted in Fig. 9 below. It is clear that all of the three methods provide consistent results by identifying and classifying well group 680 into the developed thief zone.

\section{Evaluation of the thief zone characteristics in North Buzazi Oilfield}

In the reservoirs with different thief zone levels and channeling conditions, the oil and water phases exhibit different flow and transport behaviors, resulting in different waterflood characteristics. After the identification of the thief zones based on their evolutions, we further evaluate their characteristics.

Based on the water flood characteristic curve of conventional sandstone reservoirs, the fluid transport behavior of Darcy flow and pipe flow is significantly different as shown in Fig. 10. We selected the water-oil-ratio (WOR), which is a parameter most sensitive to reservoir displacement condition and proposed two methods for pattern recognition:

\section{Method A}

Considering the injection-production well pair, given the production data of oil and water wells, the properties of the thief zones, including volume, permeability and pore throat, are calculated by combining the injected 'excess water' and the theoretical water production of the production well. It should be noted that 'excess water' is the difference between the actual water production of the production well and the theoretical water production without high water consumption band and thus could be considered as 'ineffective water'.

1. The water-oil-ratio is the mobility ratio between oil and water flow:

$$
R_{\text {woi }}=\left(K_{\mathrm{rw}} \mu_{o}\right) /\left(K_{\mathrm{ro}} \mu_{w}\right)
$$

2. The water production $\left(q_{\mathrm{wd}}\right)$ needed to form the thief zone:

$$
q_{\mathrm{w} 0}=q_{\mathrm{os}} \cdot R_{\mathrm{woi}} ; q_{\mathrm{wd}}=q_{\mathrm{ws}}-q_{w 0}
$$

3. The theoretical water production $\left(q_{\mathrm{wl}}\right)$ is derived from steady state flow equation: $q_{\mathrm{wl}}=\frac{2 \pi K_{w} h \Delta P}{\mu_{w} \ln \frac{r_{e}}{r_{w}}}$

4. The percentage of water production that does not contribute to the development of thief zone:

$N_{i}=q_{w 0} / q_{\mathrm{wl}}$

5. The volume of the thief zone can be calculated from volume balance:

$V_{d}=V_{0}\left(1-N_{i}\right)$

6. The permeability and pore radius of the thief zone:

For seepage type $: K_{d}=\frac{q_{w d} \mu_{w} l}{V_{\lrcorner} \Delta P} r_{d}=\sqrt{\frac{8 K_{d} \tau^{2}}{\phi}}$

For Pipe flow type : $K_{d}=\frac{d^{2}}{72.79 e^{6.71} \frac{\delta}{d+0.9652 \delta}}$

7. where $R_{\text {woi }}$ is the theoretical water-oil-ratio, $q_{w 0}$ is the water production in areas where thief zones are not formed and in $\mathrm{m}^{3}, q_{w d}$ is the excess water in $\mathrm{m}^{3} ; q_{w s}$ is the actual water production in $\mathrm{m}^{3} ; q_{o s}$ is the actual oil production in $\mathrm{m}^{3} ; V_{0}$ is the single well control pore volume in $\mathrm{m}^{3}$.

\section{Method B}

The concept of 'equivalent diffusion coefficient' based on 'saturation difference' is proposed, which means that the spindle-shaped distribution of injection-production streamline and its influence on reservoir permeability are equivalent to the influence of axial and lateral mass transfer and diffusion of injected water.

1. The governing equation considering equivalent mass transfer and diffusion in one-dimensional flow is written as:

$$
D \frac{\partial^{2} C}{\partial x^{2}}-u \frac{\partial C}{\partial x}=\frac{1}{1-S_{\mathrm{wc}}} \frac{\partial C}{\partial t}
$$

2. Substituing in the water content $\left(f_{w}\right)$, it can be transformed into

$$
D \frac{\partial^{2} f_{w}}{\partial x^{2}}-u \frac{\partial f_{w}}{\partial x}=\frac{1}{1-S_{\mathrm{wc}}} \frac{\partial f_{w}}{\partial t}
$$

3. Initial and boundary conditions are:

$$
\begin{aligned}
& \text { I.C. }: f_{w}(x, 0)=\left\{\begin{array}{cc}
1 & x=0 \\
f_{w 0} & x>0
\end{array}\right. \\
& \text { B.C: }\left\{\begin{array}{c}
f_{w}(0, t)=1 \quad t \geqslant 0 \\
f_{w}(\infty, t)=f_{w 0} t \geqslant 0
\end{array}\right.
\end{aligned}
$$



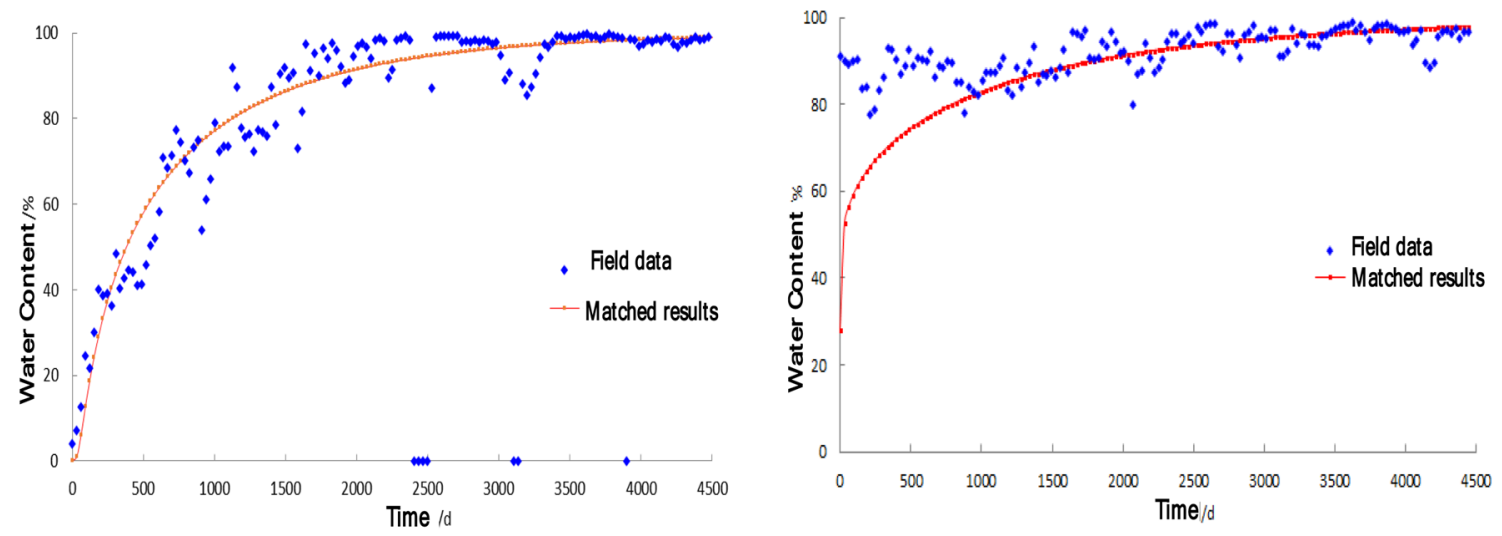

Fig. 11 Water cut curve match results for (left) well 682-2 and (right) well 662-2

4. Define a corrected time $t^{\prime}$ :

$$
t^{\prime}=\left(1-S_{\mathrm{wc}}\right) t
$$

5. Solve Eq. 16 under Eq. 18 using Laplace transformation, the water content is given as:

$f_{w}=\frac{1}{2} \operatorname{erfc}\left(\frac{x-\mathrm{ut} \prime}{2 \sqrt{\mathrm{Dt} \prime}}\right)+\frac{1}{2} \exp \frac{\mathrm{ux}}{D} \operatorname{erfc}\left(\frac{x+\mathrm{ut} \prime}{2 \sqrt{\mathrm{Dt} \prime}}\right)+f_{w 0}$

6. Define the section correction model

$\alpha=\frac{T_{k} b}{\mu_{w}} /\left(\frac{T_{k} b}{\mu_{w}}+\frac{1-b}{\mu_{o}}\right)$

7. Finally, the water content of the outflow end of the model is obtained as

$f_{w}=\frac{1}{2} \alpha \operatorname{erfc}\left(\frac{x-\mathrm{ut} \prime}{2 \sqrt{\mathrm{Dt} \prime}}\right)+f_{w 0}$

where $D$ is the equivalent diffusion coefficient in $\mathrm{cm}^{2} / \mathrm{s}$; $C$ is the proportion of water in the mixed fluid can be converted according to the water content in $\mathrm{mg} / \mathrm{L} ; u$ is the flow rate of injected fluid in $\mathrm{cm} / \mathrm{s} ; S_{\mathrm{wc}}$ is the irreducible water saturation; $t$ is time in $\mathrm{s} ; f_{\mathrm{w}}$ is the water content at the end of the outflow; $T_{\mathrm{k}}$ is the permeability difference; $b$ is the ratio of the thickness of the thief zone to the production layer where the channel is located, and unit is in \%

Table 3 Thief zone characteristics estimated from water content curve match

\begin{tabular}{llc}
\hline Well & Thief zone thick ness/m & $\begin{array}{l}\text { Perme- } \\
\text { ability } \\
\text { contrast }\end{array}$ \\
\hline $682-2$ & 6.75 & 6.1 \\
$662-2$ & 4.52 & 18.7 \\
\hline
\end{tabular}

By fitting the measured water content and the calculated water content, the property parameters such as the equivalent diffusion coefficient, thief zone thickness and permeability contrast of the thief zone can be obtained.

For illustration purpose, the water content curve match results of well 682-2 and well 662-2 are taken as examples and displayed in Fig. 11 below. From the match results given in Table 3, it is clear that well 682-2 is in a developing thief zone while $662-2$ is located in a developed thief zone, which again corroborate the identification results given in Thief zones Identificationin North Buzazi Oilfield Section

\section{Concluding remarks}

This study applies three methods to identify the thief zones in the North Buzazi Oilfield in Manghestau, Kazakhstan. Fuzzy comprehensive evaluation method is implemented based on reservoir properties and production/injection data, from which the spatial distribution of thief zones of different significance levels is obtained. A vertical heterogeneity chart is presented after applying production/injection profile method. Combined with K-means clustering algorithm, thief zones in vertical directions are identified straightforwardly using the production/injection profile data collected from a total of 512 wells in North Buzazi Oilfield. A new dimensionless pressure index (DPI) value is proposed that captures the influence of temporal evolution of the thief zones on well pressure responses. Using a total of 98 well pressure data collected in North Buzazi Oilfield, thief zones with different significance levels are identified and classified using DPI method with the help of K-means clustering algorithm. Results show that the evolution of thief zones due to the formation erosion and sand production can be successfully captured in the identification and classification tools developed on the three aforementioned methods. Good consistency is observed in the identification and classification results, 
demonstrating the reliability of these methods. After successful identifying the thief zones, we further present two ways to quantitively evaluate the properties and characteristics of thief zones, which are also shown to provide consistent and reliable estimations.

\section{Appendix A- $K$-means clustering algorithm}

$K$-means clustering algorithm is an iterative solution clustering analysis algorithm. The steps are to split the data into $K$ groups, then randomly select $K$ objects as the initial clustering centers, and then calculate the distance between each object and each seed cluster center, and assign each object to the cluster center closest to it. The cluster centers associated with the objects assigned to them represent a cluster. Each time a sample is allocated, the cluster center of the cluster is recalculated based on the existing objects in the cluster. This process will continue to repeat until a certain termination condition is met. The termination condition can be that no (or minimum number) of objects are reassigned to different clusters, no (or minimum number) of cluster centers change again, and the sum of squared errors is locally minimum.

The $K$-means clustering algorithm is generally consisted of the following steps:

(1) Choose (randomly) 4 initial points, the position of each point is (xi, yi), denoted as $P 1$;

(2) Cycle: reach the predetermined number of steps or the moving distance is less than the specified value min move:

(3) Calculate the distance between each point and the center of the category according to formula (1), the category with the smallest distance is the category of the point;

(4) According to the points of each category, recalculate the coordinate center and mark it as $P 2$;

(5) Calculate the movement distance move from $P 1$ to $P 2$, if the maximum value of the 4 moves is less than min_move, stop the loop, otherwise assign the value of $P 2$ to $\mathrm{P} 1$.

\section{Declarations}

Conflict of interest The authors declare no conflict of interest.

Open Access This article is licensed under a Creative Commons Attribution 4.0 International License, which permits use, sharing, adaptation, distribution and reproduction in any medium or format, as long as you give appropriate credit to the original author(s) and the source, provide a link to the Creative Commons licence, and indicate if changes were made. The images or other third party material in this article are included in the article's Creative Commons licence, unless indicated otherwise in a credit line to the material. If material is not included in the article's Creative Commons licence and your intended use is not permitted by statutory regulation or exceeds the permitted use, you will need to obtain permission directly from the copyright holder. To view a copy of this licence, visit http://creativecommons.org/licenses/by/4.0/.

\section{References}

Abbaszadeh-Dehghani Maghsood (1982) Analysis of unit mobility ratio well-to well tracer flow to determine reservoir heterogeneity. Stanford University

Al-Dhamen AA, Pham TR, Al-Khatib MRA (1998) A quick method of identifying and history matching a gravity dominated reservoir with localized superpermeabilities. In: Paper SPE 49276 presented at the SPE annual technical conference and exhibition, New Orleans, Louisiana, September 1998

Asadi M (2005) An Interwell Water Flood Study: Flow Pattern and Reservoir Heterogeneity Evaluation of Tamabra Formation of Poza Rica Field Area 1. Paper SPE 94226 presented at the SPE Europec/EAGE Annual Conference, Madrid, Spain, June 2005.

Calhoun JC (1953) Fundamentals of reservoir engineering. University of Oklahoma Press, Norman, pp 334-336

Felsenthal M, Gangle FJ (1975) A Case Study of Thief Zones in a California Waterflood. J Petrol Technol 27(11):1385-1391

Feng Q, Wang S, Zhang W, Song Y, Song S (2013) Characterization of high-permeability streak in mature waterflooding reservoirs using pressure transient analysis. J Pet Sci Eng 110:55-65

Fulin Z, Hongtao Z, Weimin L, Li H (1994) Application of surface pressure drawdown curves of injection wells in profile modification using clay. Oil Drill Prod Technol 02:73-76. https://doi.org/ 10.13639/j.odpt.1994.02.018

Kabir CS, Izgec B (2009) Identification and characterization of highconductive layers in waterfloods. In: Paper SPE 123930 presented at the SPE annual technical conference and exhibition, New Orleans, Louisiana, October

Li D, Yang J, Detang Lu (2016) Thief zone identification based on transient pressure analysis: a field case study. J Pet Explor Prod Technol 6:63-72

Limei W, Guoping Z, Yanxia H et al (2003) Tracer-oriented pore passage identification and remainder oil saturation distribution technologies. Fault-Block Oil Gas Field 10(4):72-73

Lu C, Jiang H, You C et al (2021) A novel method to determine the thief zones in heavy oil reservoirs based on convolutional neural network. J Pet Sci Eng 201:108471

Lu C, Jiang H, You C, et al. (2021) Determination the Levels of Thief Zones Based on Machine Learning. Paper IPTC 21176 presented at the International Petroleum Technology Conference, March 23April 1, 2021.

Sen W (2002) Research on the method of identifying advantageous channels using pressure data. MS thesis. China University of Petroleum (East China). https://doi.org/10.7666/d.y2071104

Shuxia L, Yueming C (2002) Shape features of tracer production curve. Pet Geol Recovery Effic: Engl Abstr 9(2):66-67

Vargas-Guzmán JA, Al-Gaoud A, Datta-Gupta A et al (2009) Identification of high permeability zones from dynamic data using streamline simulation and inverse modeling of geology. J Pet Sci Eng 69(3):283-291

Xiang W, Zhujun X, Hongwei Z et al (2002) Using injection profile log data to distinguish macropore formation. Well Logging Technol 26(2):162-164. https://doi.org/10.16489/j.issn.1004-1338.2002. 02.019 
Yueming C, Hanqiao J, Shuxia Li (1994) Application of well-to-well tracer test on reservoir heterogeneity description. J Univ Pet China 18(A00):1-7

Yuetian L, Baoli S, Yongsheng Y (2003) Fuzzy identification and quantitative calculation method for big pore throat. Oil Drill Prod Technol 05:54-59. https://doi.org/10.13639/j.odpt.2003.05.016
Zhilin D, Liufang Z, Zhihai Z, Wei X, Genlin T (2001) Research on the diagnosis and description of wormhole. Pet Explor Dev 1:75-77 